\section{Effect of Silane Type and Air-Drying Temperature on Bonding Fiber Post to Composite Core and Resin Cement}

Camila Maria Peres de Rosatto, Marina Guimarães Roscoe, Veridiana Resende

Novais, Murilo de Sousa Menezes, Carlos José Soares
Department of Operative Dentistry and Dental Materials, Dental School, UFU - Federal University of Uberlândia, Uberlândia, MG, Brazil

Correspondence: Prof. Dr. Carlos José Soares, Avenida Pará, 1720, Bloco 4L, Anexo A, Campos Umuarama, 38400-902 Uberlândia, MG, Brasil. Tel: +55-34-3218-2255. e-mail: carlosjsoares@umuarama.ufu.br

\begin{abstract}
This study evaluated the influence of silane type and temperature of silane application on push-out bond strength between fiberglass posts with composite resin core and resin cement. One hundred and sixty fiberglass posts (Exacto, Angelus) had the surface treated with hydrogen peroxide 24\%. Posts were divided in 8 groups according to two study factors: air-drying temperature after silane application (room temperature and 60 ${ }^{\circ} \mathrm{C}$ ) and silane type: three pre-hydrolyzed - Silano (Angelus), Prosil (FGM), RelyX Ceramic Primer (3M ESPE) and one two-component silane - Silane Coupling Agent (Dentsply). The posts $(n=10)$ for testing the bond strength between post and composite core were centered on a cylindrical plastic matrix and composite resin (Filtek Z250 XT, 3M ESPE) that was incrementally inserted and photoactivated. Eighty bovine incisor roots $(n=10)$ were prepared for testing the bond strength between post and resin cement (RelyX U100, $3 \mathrm{M}$ ESPE) and received the fiberglass posts. Push-out test was used to measure the bond strength. Data were analyzed by two-way ANOVA followed by Tukey's test $(\alpha=0.05)$. ANOVA revealed that temperature and silane had no influence on bond strength between composite core and post. However, for bond strength between post and resin cement, the temperature increase resulted in a better performance for Silane Coupling Agent, Silano and RelyX Ceramic Primer. At room temperature Silane Coupling Agent showed the lowest bond strength. Effect of the warm air-drying is dependent on the silane composition. In conclusion, the use of silane is influenced by wettability of resinous materials and prehydrolyzed silanes are more stable compared with the two-bottle silane.
\end{abstract}

Key Words: fiber post, silane, temperature, push-out bond strength, composite core, resin cement.

\section{Introduction}

Endodontically treated teeth which lost a large amount of coronal tooth substance and exposed to shear chewing forces frequently require the use of a post inside the root canal to promote retention for final restoration (1). In the last years, use of fiberglass posts in the rehabilitation of endodontically treated teeth has increased compared with other types of posts. The similar elastic modulus between fiberglass posts, resin cements, composite resin and dentin result in a better stress distribution to the remaining tooth, improving the performance of these restorations compared with metallic or ceramic posts (2). However, clinical studies have reported that the most common cause of failure is debonding of the fiberglass post from root dentin (3).

One important clinical step is silanization of the post surface after chemical or mechanical treatment (4). The main factors that influence its efficiency are the type of silane, its $\mathrm{pH}$, solvent content, silane molecule, molecule size and also the application mode (6). As a rule, organosilanes are bi-functional molecules with one end of the molecule capable of reacting with the inorganic fiberglass and the other copolymerizing with the organic resin (7).

Bond strength to fiberglass posts can be affected by different composition of silane coupling agents and the air- drying temperature (8). To accelerate the mechanism of chemical interaction between silane and the inorganic surface, the reaction may be catalyzed with temperature. Solvent evaporation plays an important role in silane performance. The presence of solvent is beneficial for promoting silane wetting, however an incomplete removal may compromise the interaction with fiberglass (9). Warm air may be used to assist evaporation of solvents and reaction products on the silane-treated surface, which results in a dry surface (10). However, the interaction between the warm air and the silane composition is not clear when this protocol is used to treat the fiberglass post surface. Moreover, there is little information about the effect of air-drying temperature on the fiberglass post surface after single and multiple bottle silane application on the interaction with resin cement or composite core.

The aim of this study was to investigate the effect of the air-drying temperature in association with different silane coupling agents on the push-out bond strength between composite resin core or resin cement to fiberglass posts. The null hypothesis is that the air-drying temperature of the post surface after silanization and the silane type have no effect on the bond strength of composite resin core or resin cement to fiberglass posts. 


\section{Material and Methods}

One hundred and sixty smooth, opaque and cylindrical/ conical fiberglass posts (Exacto; Angelus, Londrina, PR, Brazil), size 2, with a $1.5 \mathrm{~mm}$ diameter and $17.0 \mathrm{~mm}$ long were divided into sixteen experimental groups $(n=10)$ generated by 2 study factors: 1, varying air stream temperatures at two levels: silane application at room temperature $\left(23 \pm 2.0^{\circ} \mathrm{C}\right)$ and silane application at $60{ }^{\circ} \mathrm{C}$, using dry air heating; 2 , four silane coupling agents in four levels, three of them pre-hydrolyzed: Silano (Angelus, Petrópolis, RJ, Brazil); Prosil (FGM, Joinville, SC, Brazil); RelyX Ceramic Primer (3M ESPE, St. Paul, MN, USA), and one two-component silane: Silane Coupling Agent (Dentsply Ind. e Com. Ltda., Petrópolis, RJ, Brazil). The materials used for post bonding were: composite resin, represented by the post bonded to composite resin core; and resin cement, represented by the post cemented into the root canal.

\section{Post Surface Treatment}

First, all fiberglass posts were cleaned with 70\% ethanol using microbrush for $1 \mathrm{~min}$ and waiting for evaporation. Next, the posts were immersed in hydrogen peroxide 24\% (Dinâmica, Piracicaba, SP, Brazil) for 1 min (5), rinsed with an air/water jet for $30 \mathrm{~s}$ and overall drying with an air syringe. Silane was applied on post surfaces for $1 \mathrm{~min}$, according to the manufacturer's instructions (Table 1). Each silane type was used in two groups, according to the air-drying temperature. For the group kept at room temperature, specimens were gently air dried for $5 \mathrm{~s}$ with air syringe; for the $60{ }^{\circ} \mathrm{C}$ group, gentle air drying was delivered for $5 \mathrm{~s}$ using a multimeter (Minipa, model ET-1400; São Paulo, SP, Brazil) coupled a miniaturized hair dryer (Model 1808A, 50$60 \mathrm{~Hz}, 1200$ W; Sokany, Zhejiang, China). The multimeter's temperature sensor (Type $\mathrm{K}$ thermocouple) was placed in front of the hair dryer until the temperature reached 60 ${ }^{\circ} \mathrm{C}$ (Fig.1). Next, the posts were positioned close to the tip $(10 \mathrm{~mm})$ to achieve this temperature at the post surface.

\section{Specimen Preparation: Fiberglass Post - Composite Resin Core Bond Test}

After post surface treatment, each post was positioned in a device specially made to stabilize the post at an upright position. A cylindrical plastic matrix (10.0 mm long, 5.0 $\mathrm{mm}$ diameter and $1.0 \mathrm{~mm}$ thick) was placed around the post, keeping the post at the center of the tube. Next, wax was heated and poured around the matrix. The matrix was filled incrementally with a composite resin (Filtek Z250; 3M ESPE; St. Paul, MN, USA) and light curing of each 2-mm-thick increment was performed at the top of the tube using a halogen light curing unit (Optilux 501; Kerr Corporation, Orange, CA, USA) with 850 mW/ $\mathrm{cm}^{2}$ light intensity for $20 \mathrm{~s}$ (Fig. 2). The specimens were removed from the matrix with a scalpel blade and stored in distilled water at $37^{\circ} \mathrm{C}$ for $24 \mathrm{~h}$.

\section{Specimen Preparation: Fiberglass Post - Resin Cement Bond Test}

Eighty freshly extracted bovine incisors of adult animals with similar dimensions and shape were selected for this study. The selection criterion considered the similarity between the external and internal morphology of the teeth and a canal diameter less than $1 \mathrm{~mm}$ at the cervical limit. Roots $13 \mathrm{~mm}$ long were produced after removing the coronal portion of the teeth. The canals were instrumented $1 \mathrm{~mm}$ from the apex using the stepback technique, with \#2 and \#3 Gates-Glidden burs (Dentsply Maillefer, Ballaigues, Switzerland) with 0.7 and $0.9 \mathrm{~mm}$ diameter, respectively. Gates-Glidden \#4 bur with $1.1 \mathrm{~mm}$, was used at only $10 \mathrm{~mm}$ length of the root to facilitate the later post drill passage. The prepared canals had an approximate diameter of 1.5 $\mathrm{mm}$ in the cervical third and $0.9 \mathrm{~mm}$ in the middle and apical thirds. Root canals were irrigated with $1 \%$ sodium hypochlorite (Biodinâmica, Londrina, PR, Brazil). After final irrigation with saline, canals were dried with absorbent papers, filled with gutta-percha (Dentsply-Maillefer) and calcium hydroxide-based endodontic sealer (Sealer 26; Dentsply, Petrópolis, RJ, Brazil) (Fig. 3). Immediately after filling, root canals were prepared to ensure a standardized space for post insertion. Initial relief was performed removing gutta-percha using a heated endodontic plugger (Dentsply Maillefer, Ballaigues, Switzerland) and next was provided access for a \#2 post drill to a depth of $10.0 \mathrm{~mm}$.

Table 1. Silane type and manufacturer's instructions

\begin{tabular}{lc}
\hline Silane type & Manufacturer's instructions \\
\hline Silano & Clean with alcohol and dry with air. Apply silane with a brush, wait 1 min and gently dry with air \\
Prosil & Clean with alcohol and dry with air. Apply silane with a brush, wait 1 min and gently dry with air \\
RelyX Ceramic Primer & Clean post with alcohol, air dry, apply silane with a brush and gently air dry \\
Silane Coupling Agent & Mix a drop of Silane Primer and a drop of Silane Activator for 10 to 15 s. Let stand for 5 min. \\
Apply a thin layer on the surface of post and air dry. Apply a second coat and air dry
\end{tabular}


During preparation of the canal, $3.0 \mathrm{~mm}$ of the endodontic filling was left at the apex of each canal. Final irrigation was also accomplished with saline. Excess water in the root canal was dried with absorbent paper points.

For fiberglass post cementation was used the selfadhesive resin cement (RelyX U100; 3M ESPE). The resin cement was mixed as recommended by manufacturer and applied onto the post surface and into the root canal with stainless steel K-files. The post was then inserted into the root canal with digital pressure. All posts were gently inserted and held in position with pressure for 3 min. Excess cement was removed after the first minute and light-curing was performed for $40 \mathrm{~s}$ on incisal, buccal and lingual surfaces, totaling $120 \mathrm{~s}$. After the cementation procedures had been performed, specimens were stored in distilled water at $37^{\circ} \mathrm{C}$ for $24 \mathrm{~h}$.

\section{Push-Out Testing}

After the storage period, for the resin cement groups, the roots were sectioned perpendicular to their long axis
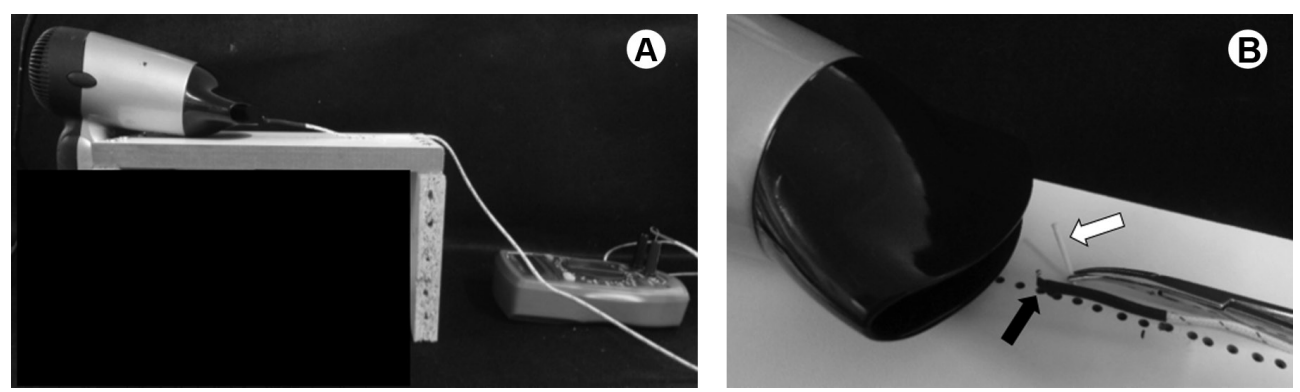

Figure 1. Application of air-drying temperature on post. A: Apparatus with hair dryer and multimeter and J type thermocouple. B: Post in front of hair dryer and next to the thermocouple.
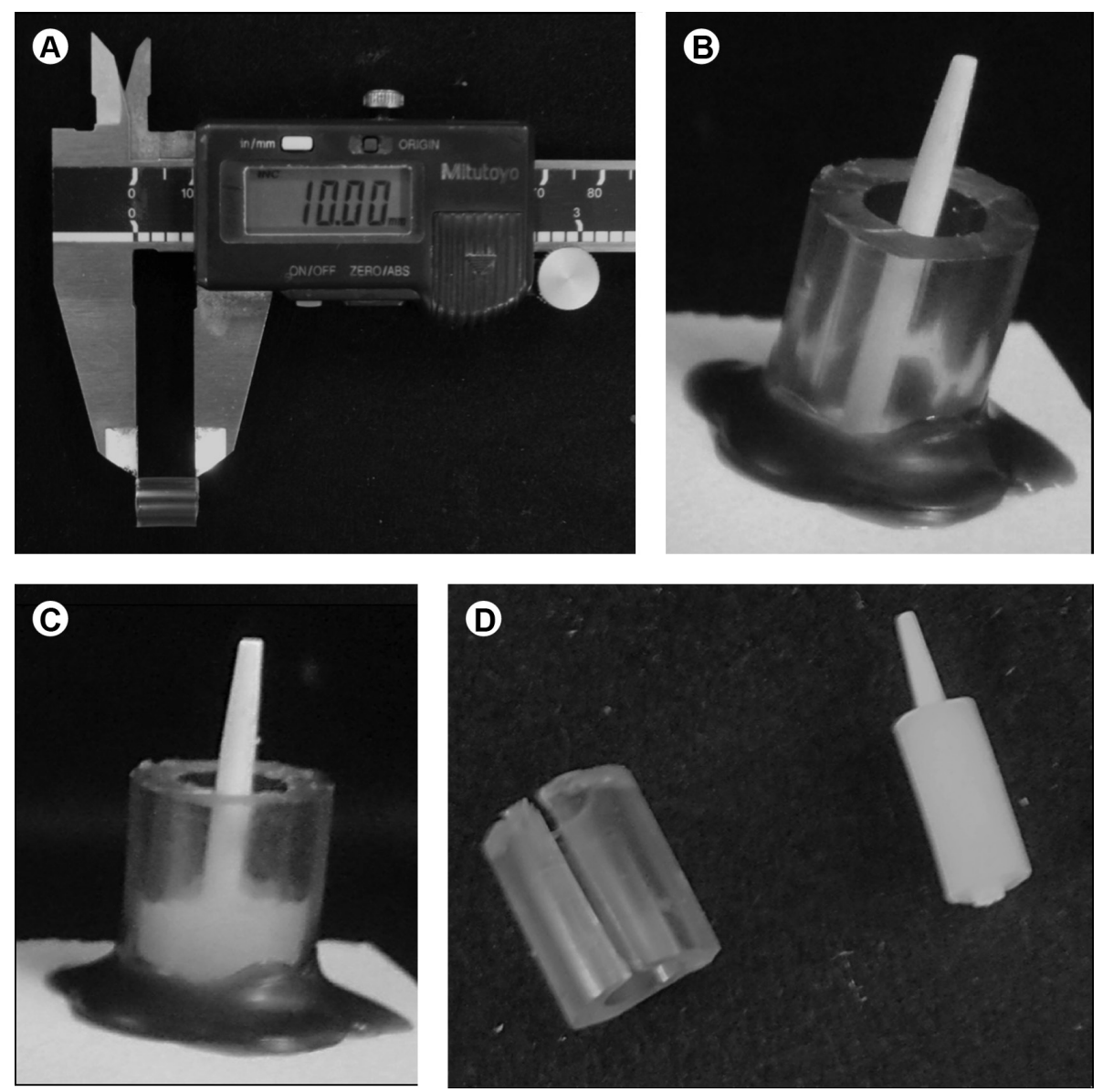

Figure 2. Composite resin core group preparation. A: Cutting plastic cylindrical matrix with $10 \mathrm{~mm}$. B. Post and plastic cylindrical matrix ready to receive composite resin. C: Composite resin inserted incrementally. D: Composite resin with standardized shape around the post. 
with a slow-speed diamond saw (Isomet 1000; Buehler, Lake Bluff, IL, USA) resulting in 6 slices $1.00 \pm 0.07 \mathrm{~mm}$ thick for each root depth. For composite resin core testing, each specimen was cut perpendicular to the long axis into 6 slices of $1.00 \pm 0.05 \mathrm{~mm}$. The slices were analyzed using optical microscopy at 40x magnification (Mitutoyo, Kanagawa, Japan) to measure both major and minor post diameters in millimeters and to identify any cracks or failures. The bonding surface was calculated considering that $\pi$ is the constant $3.14 ; R_{1}$ is the larger radius; $R_{2}$, the smaller radius; and $h$ the thickness, and using the formula of a conical frustum (11): Area $=\pi\left(R_{1}+R_{2}\right) \sqrt{ }\left(R_{1}-R_{2}\right)^{2}+h^{2}$.

A compressive push-out load was applied using a custom-built device that consisted of a stainless steel base with a center hole. The slice was centered over this hole before applying a compressive load at $0.5 \mathrm{~mm} / \mathrm{min}$ with a circular load applicator tip placed in the upper portion of the testing machine (EMIC DL2000; EMIC, São José dos Pinhais, PR, Brazil) and perpendicular to the specimen, touching only the surface on the fiberglass post. For the resin cement groups, the size of the hole and load applicator tip varied, due to the conical shape of the root canal after it had been prepared by the post drill, aiming to normalize the distance of the load point at the interface. In cervical and middle third the base had a $2.5 \mathrm{~mm}$ diameter and the load applicator tip was $1.0 \mathrm{~mm}$. In apical third, the diameters were $2.0 \mathrm{~mm}$ for base and $0.75 \mathrm{~mm}$ for tip. The load was applied in the apical-coronal direction, pushing the post through the largest side of the specimen. The failure was demonstrated by extruding the post or the fracture of specimen. The force required to cause failure $(\mathrm{N})$ was recorded by a $200 \mathrm{~N}$ load cell hardwired to software (TESC; EMIC). The push-out bond strength was expressed in $\mathrm{MPa}$ by dividing the load $(\mathrm{N})$ at failure by the bonded area of the post segment $\left(\mathrm{mm}^{2}\right)(12,13)$.

\section{Statistical Analysis}

Data were analyzed by two-way ANOVA to evaluate

Table 2. Mean (MPa) and standard deviation values of bond strength between fiber post to composite core for all groups

\begin{tabular}{lcc}
\hline \multirow{2}{*}{ Silane type } & \multicolumn{2}{c}{ Air-drying temperature } \\
\cline { 2 - 3 } & Room temperature & $60{ }^{\circ} \mathrm{C}$ \\
\hline Silane Coupling Agent & $16.9(2.6)^{\text {Aa }}$ & $14.7(2.8)^{\text {Aa }}$ \\
Silano & $15.7(2.1)^{\text {Aa }}$ & $13.6(2.8)^{\text {Aa }}$ \\
Prosil & $16.4(2.6)^{\text {Aa }}$ & $15.0(2.6)^{\text {Aa }}$ \\
RelyX Ceramic Primer & $16.5(2.7)^{\text {Aa }}$ & $15.5(2.8)^{\text {Аa }}$ \\
\hline
\end{tabular}

Different uppercase letters in columns and lowercase letters in rows indicate statistically significant difference at $p<0.05$. the effect of the study factors (silane and temperature). Two analyses were performed, first the two-way ANOVA without the control group. Multiple comparisons of means were performed with Tukey Honestly Significant Difference (HSD) test $(\alpha=0.05)$.

\section{Confocal Microscopy Analysis of Failure Mode}

After push-out testing, the specimens of resin cement groups were analyzed under confocal microscopy (LM 510 Meta; Zeiss, Jena, Germany) to determine the failure mode. The specimens received no previous treatment for microscopic analysis, since they reflect natural fluorescence. The failure mode was established as (Fig. 4): 1) adhesive between post and resin cement (no resin cement visible around the post); 2) adhesive between resin cement and dentin (post enveloped by resin cement); 3) cohesive in cement; 4) cohesive in dentin; and 5) mixed. For the composite resin core specimens the failure mode was labeled like: 1) adhesive between post and composite resin; 2) cohesive in composite resin; and 3) mixed.

\section{Results}

For the composite resin core group, the mean and standard deviation values of bond strength for all experimental groups are shown in Table 2. Two-way ANOVA showed no significant effect for the temperature factor $(p=0.158)$, for the silane factor $(p=0.610)$, neither for the interaction between both factors $(p=0.668)$.

The mean and standard deviation values of bond strength for all experimental resin cement groups are shown in Table 3. For the resin cement groups, two-way ANOVA showed significant difference for the temperature factor $(p<0.001)$, and for the interaction between silane and temperature $(p<0.001)$, but no difference was found for silane factor $(p=0.115)$. The Tukey HSD test showed that when the silanes were used at room temperature, the nonhydrolyzed silane (Silane Coupling Agent) had significantly lower bond strength than all other tested pre-hydrolyzed

Table 3. Mean (MPa) and standard deviation values of bond strength between fiber post to resin cement for all groups

\begin{tabular}{|c|c|c|}
\hline \multirow{2}{*}{ Silane type } & \multicolumn{2}{|c|}{ Air-drying temperature } \\
\hline & Room temperature & $60{ }^{\circ} \mathrm{C}$ \\
\hline Silane Coupling Agent & $14.2(2.3)^{\mathrm{Bb}}$ & $21.4(6.1)^{\mathrm{Aa}}$ \\
\hline Silano & $17.9(2.4)^{\mathrm{Ab}}$ & $22.9(4.1)$ Аa \\
\hline Prosil & $18.8(5.2)^{\text {Аа }}$ & $20.6(5.5)^{\text {Аa }}$ \\
\hline RelyX Ceramic Primer & $19.0(4.1)^{\mathrm{Ab}}$ & $25.5(4.5)$ Аа \\
\hline
\end{tabular}

Different uppercase letters in columns and lowercase letters in rows indicate statistically significant difference at $p<0.05$. 
silanes. However, associated the silanes were used at $60{ }^{\circ} \mathrm{C}$ no difference was found among all groups. The use of warm drying resulted in significantly higher bond strength for Silane Coupling Agent, Silano and RelyX Ceramic Primer, but no influence was found for Prosil (Table 3).

Confocal laser microscopy observations showed that adhesive failures decreased significantly when warm air- drying was used for all silane groups. Mixed and adhesive failure between resin cement and post were the most prevalent failures for all groups. Mixed failure involving partial adhesive failure between post and composite resin core was the exclusive failure mode in all specimens of composite resin core specimens, irrespective of air drying temperature and silane type (Table 4).
Table 4. Distribution of failure types (\%) of fiber posts to resin cement.

\begin{tabular}{|c|c|c|c|c|c|c|c|c|c|c|}
\hline \multirow{3}{*}{ Silane type } & \multicolumn{10}{|c|}{ Air-drying temperature } \\
\hline & \multicolumn{5}{|c|}{ Room temperature } & \multicolumn{5}{|c|}{$60^{\circ} \mathrm{C}$} \\
\hline & 1 & 2 & 3 & 4 & 5 & 1 & 2 & 3 & 4 & 5 \\
\hline Silane Coupling Agent & 15 & 7 & 35 & 0 & 43 & 2 & 28 & 25 & 0 & 45 \\
\hline Silano & 12 & 22 & 32 & 0 & 35 & 3 & 30 & 27 & 2 & 38 \\
\hline Prosil & 22 & 28 & 25 & 0 & 25 & 7 & 28 & 18 & 0 & 47 \\
\hline RelyX Ceramic Primer & 10 & 22 & 23 & 0 & 45 & 5 & 22 & 23 & 2 & 48 \\
\hline
\end{tabular}

\section{Discussion}

The null hypothesis was rejected. Application of a warm air stream at $60{ }^{\circ} \mathrm{C}$ on the fiberglass post surface after silanization and the silane type had significant influence on the bond strength to resin cement. However, no influence was found for both study factors when the bond strength between composite resin core and fiberglass post was tested.

This study tested the bond strength between fiberglass post and both resinous materials commonly used to restore endodontically
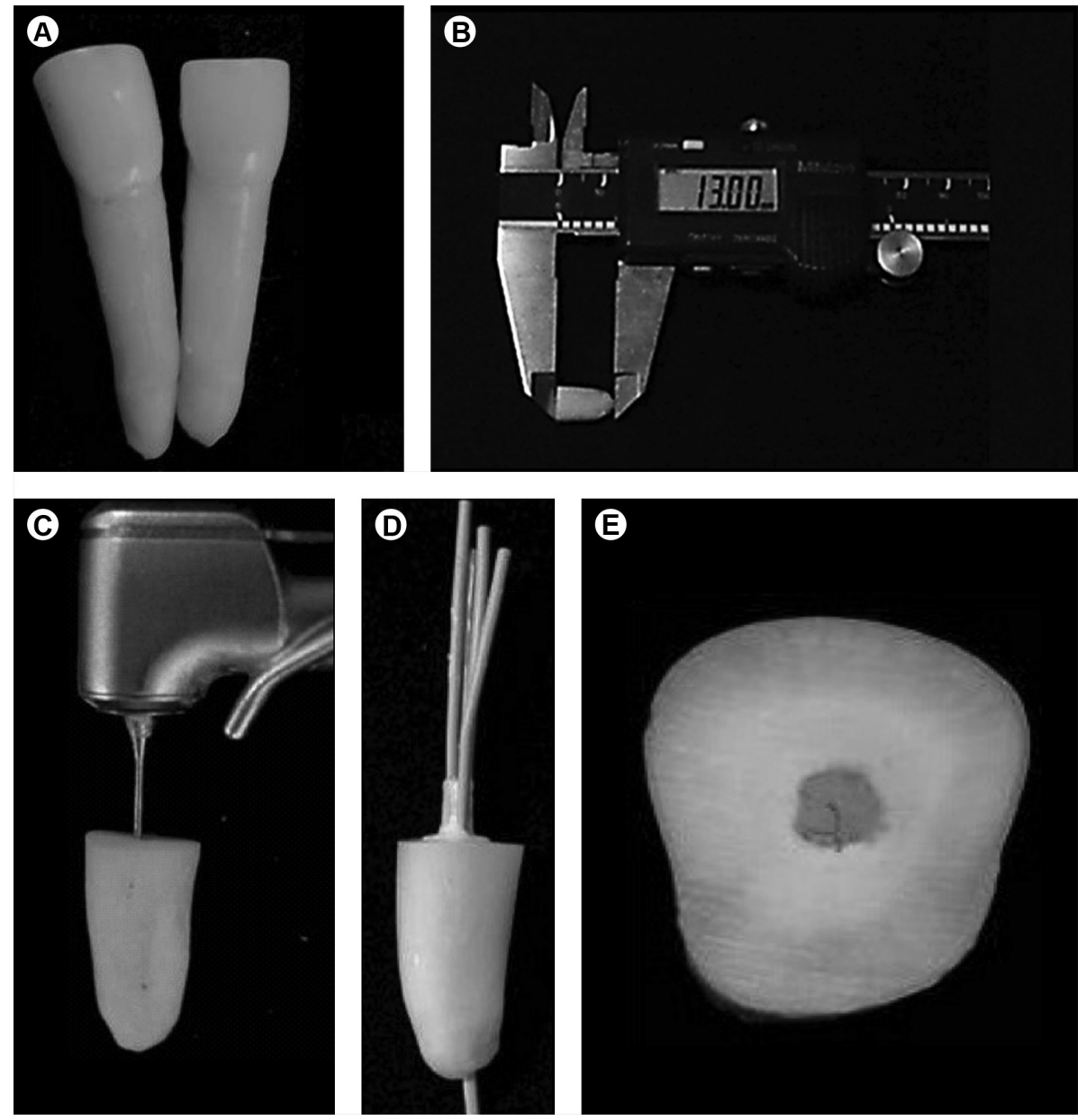

Figure 3. Resin cement group preparation. A: bovine incisors with similar dimension and shape. B: Root without coronal portion measuring $13 \mathrm{~mm}$; (C) Canal instrumentation using a stepback technique, $1 \mathrm{~mm}$ from the apex. D: Root canal filling. E: 1-mm-thick dentin/post slice. 
treated teeth, composite resin core and resin cement. Interaction between resin cement and post is of utmost importance to determine retention of the post in the root canal (14). On the other hand, interaction between fiberglass post and composite resin core is essential to support the coronal reconstruction (4). Previous studies reported that in order to accelerate and improve the chemical interaction between silane and the inorganic surface, the reaction might be catalyzed by acid treatment or temperature (15). Drying with warm air at $38{ }^{\circ} \mathrm{C}$ has been demonstrated to increase the effectiveness of silane coupling agents when bonding ceramic to composite resin (16). Another similar study reported that treatment with temperature at $100{ }^{\circ} \mathrm{C}$ for $60 \mathrm{~s}$ following surfaceroughening treatment improved the shear bond strength between these materials (8). Additionally, the use of silane drying with a warm air stream at $45^{\circ} \mathrm{C}$ was able to enhance the microtensile bond strength of a leucite-reinforced glass-ceramic (10).

Observing such previous results, it was expected that treatment with $60{ }^{\circ} \mathrm{C}$ temperature would increase the effectiveness of silane coupling agents when used to treat fiberglass posts. However, the results of the present study showed that the warm air stream at $60^{\circ} \mathrm{C}$ had no effect on the bond strength between fiberglass post and composite resin core. Novais et al (2011) found similar results (17). This may be explained by the absence of adhesive system layer application before the incremental insertion of the composite resin, in order to avoid interference between the study factors. The composite resin used to build the core is normally a composite with higher filler content and then the use of adhesive system should be recommended and considered as a limitation of this study. The resin cement is more fluid resulting in a better interaction with the surface treated by hydrogen peroxide and silane. Then the push-out test was able to detect significant influence on both study factors when the bond strength to resin cement was tested.

The most commonly used silane in dentistry consists of 3- trimethoxysilylpropylmethacrylate (MPS) diluted in a water-ethanol solution. Both types of silane, the prehydrolyzed form (one bottle) or in a form where hydrolysis can occur by mixing silane and acid (two bottles), are reported to perform well, even though atmospheric moisture is nor favorable for the pre-hydrolyzed silanes (18). Nevertheless, the two-bottle systems increase the shelf life of silanes in comparison with one-bottle systems (19). However, the entire silane reaction mechanism still remains a not fully understood subject (6). In this study it was found that when the two-bottle silane, Silane Coupling Agent, was used at room temperature the bond strength was significantly lower than the other tested pre-hydrolyzed silanes. This result may be explained by the limitation of the reaction at room temperature during manipulation of the compounds. When temperature is applied the reaction may
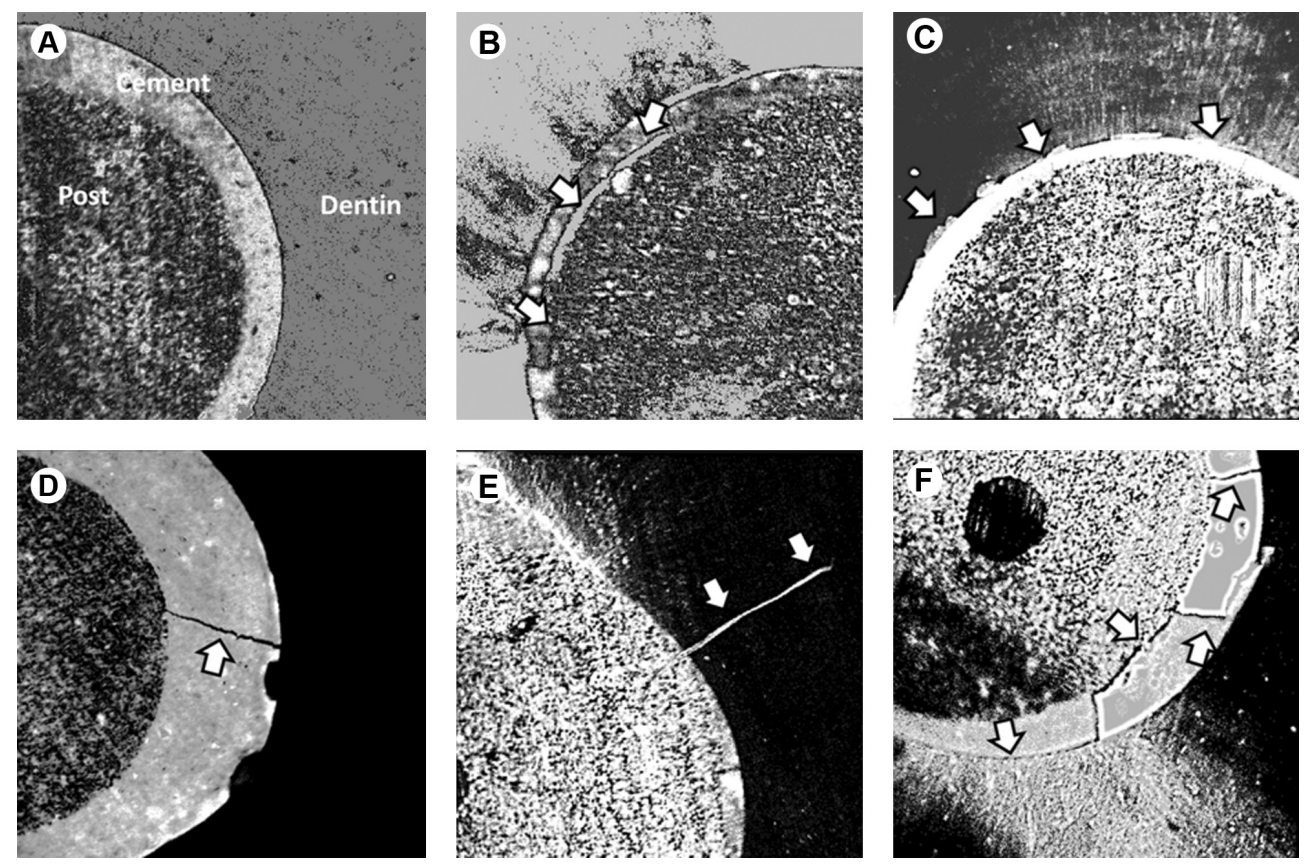

Figure 4. Confocal laser scanning microscopy images. A: Representative image showing the post, resin cement and dentin. B: Representative specimen of failure type 1 - arrows indicate adhesive failure between post and resin cement. C: Representative specimen of failure type 2 - arrows indicate adhesive failure between resin cement and dentin. D: Representative specimen of failure type 3 - arrow indicates cohesive failure in cement. E: Representative specimen of failure type 4 - arrows indicate cohesive failure in dentin. F: Representative specimen of failure type 5 - arrows indicate mixed adhesive failure between dentin and luting material. 
be completed and the residual solvent may be eliminated, improving the bond strength.

In order to improve the bond strength between silane and the epoxy resin matrix of fiberglass posts, surface treatment procedures have been investigated (5). The etching effect of hydrogen peroxide depends on its capacity to partially dissolve the resin matrix, breaking epoxy resin bonds and exposing the surface of fibers to silanization by a mechanism of substrate oxidation $(4,20)$. Carvalho et al. (21) reported that the greatest gain in bond strength was due to etching. These findings indicate the importance of etching prior to silane application (21). Silane has been a medium of choice to provide chemical interaction between dental composites and dental ceramics, resulting in a strong bond between the resinous materials and different substrates (15).

The quality of adhesion using silane coupling agents does not depend only on the specifications of the silane, such as $\mathrm{pH}$, concentration, nature of the solvent and hydrolysis time, but also on the application protocol, such as drying conditions, time between application of silane and adhesive resin, temperature and humidity of the environment (22). Temperature rise eliminates alcohol, water and other byproducts in their composition (10). One factor that may influence the silane effectiveness is incomplete solvent evaporation (23). The ideal warm air drying to achieve this effect probably varies according to the solvent type for each type of silane. The two-component Silane Coupling Agent (Dentsply) had ethanol as main solvent, so when temperature rises the ethanol solvent evaporates more, as compared with other silanes such as Prosil (FGM) and RelyX Ceramic Primer (3M ESPE) that contain water in their composition. Despite the basic composition of commercially available silane materials being similar, it seems that the differences between the solvents could have influenced the results of this study. In vitro tests are mandatory to evaluate commercially available materials. However this in vitro study had some limitations. Thermal cycling may be interesting to perform prior to the bond strength test. The authors chose to isolate the study factor by removing the adhesive system application before resin composite. Therefore future studies should be conducted to investigate the influence of the adhesive system and the thermal cycling and the differences between restorative materials, posts and their interfaces, to enhance the formulation of protocols of post cementation. The other aspect that might be seen as a limitation of this study is that only one type of resin cement was tested, but it is possible to extrapolate these results for other resin cement types, because the compositions are similar. In the past decade, self-adhesive resin cements were introduced to provide easier clinical application compared with regular resin cements (25).
Multiple steps might just make the procedures harder and more time-consuming. The use of self-adhesive resin cements, however, appears to be a suitable and perhaps a less technique-sensitive option than luting strategies that involve pre-treating the canals with adhesive solutions (24). Furthermore, dual-cure mechanism of self-adhesive resin cements has the advantage of presenting both types of polymerization, chemical and physical, making the luting safer.

In conclusion, this study showed that drying temperature and silane type had only influence on the bond strength between post and resin cement. The use of warm air-drying resulted in a better performance for Silane Coupling Agent, Silano and RelyX Ceramic Primer. The effect of silane is influenced by wettability of resinous materials and pre-hydrolyzed silanes are more stable compared to the two-bottle silanes.

\section{Resumo}

Este estudo avaliou a influência do tipo de silano e a aplicação de temperatura no silano na resistência de união por push-out entre pinos de fibra de vidro com núcleo de preenchimento em resina composta e cimento resinoso. Cento e sessenta pinos de fibra de vidro (Exacto, Angelus, Londrina, PR, Brasil) receberam tratamento de superfície com peróxido de hidrogênio a $24 \%$. Os pinos foram divididos em 8 grupos com dois fatores em estudo: temperatura de secagem de ar após a aplicação do silano (temperatura ambiente e $60^{\circ} \mathrm{C}$ ) e o tipo de silano: três pré-hidrolisados - Silano (Angelus), Prosil (FGM), RelyX Ceramic Primer (3M ESPE) e um silano de dois frascos - Silane Coupling Agent (Dentsply). Para o teste de resistência de união entre pino e núcleo de preenchimento, os pinos $(n=10)$ foram centralizados em uma matriz plástica cilindrica e a resina composta (Filtek Z250 XT, 3M ESPE) foi incrementalmente inserida e fotopolimerizada. Para o teste de resistência de união entre pino e cimento resinoso (RelyXU100, 3M ESPE) 80 raizes de incisivos bovinos $(n=10)$ foram preparadas e receberam os pinos de fibra de vidro. Teste de push-out foi usado para mensurar a resistência de união. Os dados foram analisados por ANOVA fatorial seguido do teste de Tukey $(\alpha=0,05)$. Temperatura e silano não tiveram influência na resistência de união entre núcleo de preenchimento e pino. Entretanto, para a resistência de união entre pino e cimento resinoso, o aumento da temperatura resultou em um melhor desempenho para Silane Coupling Agent, Silano e RelyX Ceramic Primer. Além disso, na temperatura ambiente Silane Coupling Agent teve a menor resistência de união. 0 efeito da secagem de ar quente é dependente da composição do silano. Concluindo, o uso do silano é influenciado pela molhabilidade dos materiais resinosos e os silanos pré-hidrolisados são mais estáveis comparados ao silano de dois frascos.

\section{Acknowledgements}

This study received financial support from CNPq and FAPEMIG. The authors are indebted with Angelus for donating the fiberglass posts and 3M-ESPE for the silane. The authors deny any conflicts of interest.

\section{References}

1. Schwartz RS, Robbins JW. Post placement and restoration of endodontically treated teeth: a literature review. J Endod 2004;30:289301.

2. Grandini S, Goracci C, Tay FR, Grandini R, Ferrari M. Clinical evaluation of the use of fiber posts and direct resin restorations for endodontically treated teeth. Int J Prosthodont 2005;18:399-404. 
3. Cagidiaco MC, Goracci C, Garcia-Godoy F, Ferrari M. Clinical studies of fiber posts: a literature review. Int J Prosthodont. 2008;21:328-336.

4. Vano M, Goracci C, Monticelli F, Tognini F, Gabriele M, Tay FR, et al.. The adhesion between fibre posts and composite resin cores: the evaluation of microtensile bond strength following various surface chemical treatments to posts. Int Endod J 2006;39:31-39.

5. de Sousa Menezes M, Queiroz EC, Soares PV, Faria-e-Silva AL, Soares CJ, Martins LR. Fiber post etching with hydrogen peroxide: effect of concentration and application time. J Endod 2011;37:398-402

6. Matinlinna JP, Lassila LV, Ozcan M, Yli-Urpo A, Vallittu PK. An introduction to silanes and their clinical applications in dentistry. Int J Prosthodont 2004;17:155-164.

7. Oliveira AS, Ramalho ES, Ogliari FA, Moraes RR. Bonding self-adhesive resin cements to glass fibre posts: to silanate or not silanate? Int Endod J 2011:44:759-763

8. Roulet JF, Soderholm KJ, Longmate J. Effects of treatment and storage conditions on ceramic/composite bond strength. J Dent Res 1995;74:381-387.

9. de la Fuente JL, Madruga EL. A kinetic study of free-radical copolymerization of butyl acrylate with methyl methacrylate in solution. Macrom Chem Phys 1996;197:3743-3755.

10. Shen $\mathrm{C}, \mathrm{Oh} \mathrm{W}$, Williams JR. Effect of post-silanization drying on the bond strength of composite to ceramic. J Prosthet Dent 2004;91:453458.

11. Bitter K, Priehn K, Martus P, Kielbassa AM. In vitro evaluation of pushout bond strengths of various luting agents to tooth-colored posts. J Prosthet Dent 2006;95:302-310.

12. Goracci C, Tavares AU, Fabianelli A, Monticelli F, Raffaelli O, Cardoso $\mathrm{PC}$, et al.. The adhesion between fiber posts and root canal walls: comparison between microtensile and push-out bond strength measurements. Eur J Oral Sci 2004;112:353-361.

13. Soares CJ, Santana FR, Castro CG, Santos-Filho PC, Soares PV, Qian

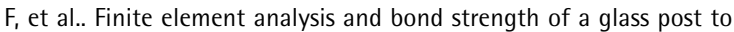
intraradicular dentin: comparison between microtensile and push-out tests. Dent Mater 2008;24:1405-1411.

14. Hikita K, Van Meerbeek B, De Munck J, Ikeda T, Van Landuyt K, Maida T, et al.. Bonding effectiveness of adhesive luting agents to enamel and dentin. Dent Mater 2007:23:71-80.
15. Fabianelli A, Pollington S, Papacchini F, Goracci C, Cantoro A, Ferrari $M$ et al.. The effect of different surface treatments on bond strength between leucite reinforced feldspathic ceramic and composite resin. $J$ Dent 2010;38:39-43.

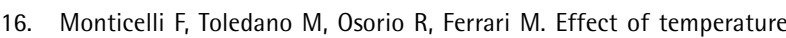
on the silane coupling agents when bonding core resin to quartz fiber posts. Dent Mater 2006;22:1024-1028.

17. Novais VR, Simamoto Júnior PC, Rontani RMP, Correr-Sobrinho L, Soares CJ. Bond strength between fiber posts and composite resin core - Influence of temperature on silane coupling agents. Braz Dent J 2011;23:8-14.

18. Anagnostopoulos $T$, Eliades G, Palaghias G. Composition, reactivity and surface interaction of three dental silane primers. Dent Mater 1993;9:182-190.

19. Matinlinna JP, Lung CYK. Aspects of silane coupling agents and surface conditioning in dentistry: An overview. Dent Mater 2012;28:467-477.

20. Monticelli F, Toledano M, Tay FR, Sadek F T, Goracci C, Ferrari M. A simple etching technique for improving the retention of fiber posts to resin composites. J Endod 2006;32:44-47.

21. Carvalho RF, Martins MEMN, Queiroz JRC, Leite FPP, Ozcan M. Influence of silane heat treatment on bond strength of resin cement to a feldspathic ceramic. Dent Mater J 2011;30:392-339.

22. Abel ML, Allington LD, Digby RP, Porritt N, Shaw SJ, Watts JF. Understanding the relationship between silane application conditions, bond durability and locus of failure. Int J Adhes Adhes 2006;26:2-15.

23. Monticelli $F$, Toledano $M$, Tay FR, Cury AH, Goracci C, Ferrari M. Post-surface conditioning improves interfacial adhesion in post/core restorations. Dent Mater 2006;22:602-609.

24. Sarkis-Onofre R, Skupien JA, Cenci MS, Moraes RR, Pereira-Cenci T. The role of resin cement on bond strength of glass-fiber posts luted into root canals: a systematic review and meta-analysis of in vitro studies. Oper Dent 2014;39:E31-E44.

25. Ferracane JL, Stansbury JW, Burke FJ. Self-adhesive resin cements - chemistry, properties and clinical considerations. J Oral Rehabil 2011;38:295-314. 